\title{
Explaining health system responses to public reporting of cardiac surgery mortality in England and the USA
}

\author{
Mark Exworthy ${ }^{1 \star}$ (D), Jon Gabe ${ }^{2}$ (D), Ian Rees Jones ${ }^{3}$ (D) and Glenn Smith ${ }^{4}$ \\ ${ }^{1}$ Health Services Management Centre, University of Birmingham, Birmingham, UK, ${ }^{2}$ Royal Holloway University of London, \\ Egham, UK, ${ }^{3}$ Cardiff University, Cardiff, UK and ${ }^{4}$ Imperial College, London, London, UK \\ ${ }^{*}$ Corresponding author. Email: M.Exworthy@bham.ac.uk
}

(Received 26 July 2017; revised 28 July 2020; accepted 24 November 2020; first published online 18 January 2021)

\begin{abstract}
Public reporting of clinical performance is increasingly used in many countries to improve quality and enhance accountability of the health system. The assumption is that greater transparency will stimulate improvements by clinicians in response to peer pressure, patient choice or competition. The international diffusion of public reporting might suggest greater similarity between health systems. Alternatively, national and local contexts (including health system imperatives, professional power and organisational culture) might continue to shape its form and impact, implying continued divergence. The paper considers public reporting in the USA and England through the lens of Scott's 'pillars' institutional framework. The USA was arguably the first country to adopt public reporting systematically in the late 1980s. England is a more recent adopter; it is now being widely adopted through the National Health Service (NHS). Drawing on qualitative data from California and England, this paper compares the behavioural and policy responses to public reporting by health system stakeholders at micro, meso and macro levels and through the intersection of ideas, interests, institutions and individuals through. The interplay between the regulative, normative and cultural-cognitive pillars helps explain the observed patterns of on-going divergence.
\end{abstract}

Key words: California; cardiac surgery; England; public reporting

The growing prevalence of discourses on transparency is becoming 'irresistible' (Marshall et al., 2003: 145) and being reinforced policy and practice in many health systems ( $\mathrm{Tu}$ and Cameron, 2003; Blomgren, 2007; Clarke and Oakley, 2007; Levay and Waks, 2009; Pelone and Riccardi, 2013; Kraska et al., 2016). However, there has been limited comparative evidence of the behavioural responses to public reporting by health system stakeholders, and explanation of those responses (Marshall et al., 2003) and hardly any conceptual analysis of what these developments mean for the medical profession or health systems. This paper seeks to remedy those gaps in knowledge in relation to public reporting of the outcomes of cardiac surgery in England and California.

The paper is organised into three main sections. First, we examine the emergence and development of public reporting as a form of transparency and accountability. We also present a conceptual framework of institutional change by which these developments may be understood. Second, we present two qualitative case studies to examine the behavioural responses of stakeholders following the inception of public reporting of mortality associated with cardiac surgery. These case studies examine the responses to public reporting at the micro, meso and macro levels in the English and Californian health systems. Third, we interpret these findings in terms of the conceptual framework. 


\section{Understanding public reporting in context}

In the past two decades, transparency and openness have become commonplace features of most health systems. Arguably, the prime example of transparency in health systems is the public reporting of (medical or surgical) performance. The dissemination of process and/or outcome measures to the public via the internet represents a major shift for health system policy-makers, the staff that work in them and the patients treated by them. This paper examines the responses by surgeons, health care executives and policy-makers to public reporting in England and California. (Patient perspectives are not included in this study.)

Underlying the emergence of public reporting in health systems is a series of socio-political and cultural changes (Exworthy et al., 2010). First, trust in medical professionals (and the wider health system) has been undermined by a series of 'scandals' which have often revolved around the way in which (medical) performance is managed, usually by their peers (Scott and Ward, 2006; Calnan and Rowe, 2008; Timmermans and Oh, 2010; Dixon-Woods et al., 2011). As a result, doctors in many health systems are no longer in sole charge of determining standards of (their) performance, monitoring those standards and taking action to remedy 'poor' or reward 'good' practice.

Second, advances in information technology have fostered the emergence of public reporting. The ability to accumulate, store and disseminate comparative data to public audiences has enabled medical practice to become auditable and comparable (Power, 1997; Waring and Currie, 2009; Jeacle and Carter, 2011).

Third, the advent of 'new public management' (in many health systems) has instituted new forms of accountability and effectiveness, which are often promulgated by clinical hybrid managers (Lynn, 1998; Llewellyn, 2001). Neo-liberal policies of 'consumer' choice and competition have placed greater emphasis on market-based approaches in health systems (Davis et al., 1995). Both choice and competition have had limited impacts but have challenged professional ownership of medical performance (Greener, 2003; Bevan et al., 2019). Cost containment has also been implicit in discourses of new public management and so public reporting has been framed, to some extent, by this. Often, this has been described as a search for better value health care (Gray, 2011).

Fourth, the growth of a consumerist culture has 'encouraged patients to become proactive and informed about the choices they make regarding their health by accessing independent knowledge' (Gabe et al., 2012; also Roberts, 1999).

Collectively, these changes have made transparency a normative doctrine in health systems; stakeholders 'must' claim the need for greater transparency as if being against it would be morally corrupt (Hood, 2007; Meijer, 2009). This is despite questions about its definition, implementation and consequences. For example, clinicians could manipulate the data and/or their behaviour if incentives become too explicit (Smith, 1995). Similarly, the surfeit of (often, esoteric) information might also constrain patients in their health care decision-making (Tsoukas, 1997; Strathern, 2000). Therefore, public reporting may not necessarily lead to 'improvements' (Pawson, 2002).

The advent of public reporting has been enabled by these developments but, for it to be effective at improving performance, it requires the presence of key factors, namely the widespread availability of information on a regular basis and the clear presentation of performance rankings (Hibbard, 2008; Bevan et al., 2019). This 'programme theory' of public reporting thus relies on four stages: identification, naming, sanction and recipient response (Pawson, 2002; Exworthy et al., 2010). However, each has potential unintended consequences which might subvert the overall effectiveness of public reporting: culprit misidentification, dissemination dissimulation, sanction misapplication and unintended outcome.

The origins of contemporary public reporting in health care can be traced back to developments in Pennsylvania and New York states in the 1980s (Chassin, 2002; Hussey et al., 2014). California represents a particularly advanced example of public reporting in the USA (compared to other states), having been in operation for over two decades. The diffusion and transfer of this 
policy within the USA and to other countries took place during the 1990s and 2000s (Dolowitz et al., 1999). For example, in recent decades, the English health system has become more attuned to US health policy developments including public reporting (Marshall et al., 2000; Walshe, 2001; Ham, 2005; Exworthy. and Freeman, 2009; Oliver and Brown, 2011). There has been a notable focus on comparisons between the UK and the USA (e.g. Ham, 2005; Exworthy et al., 2006; Exworthy and Freeman, 2009; Oliver and Brown, 2011; Bevan and Fasolo, 2013) and specifically, England and California (e.g. Feachem et al., 2002). (The English reference here is deliberate since greater divergence has been apparent in the devolved nations of the UK (Greer, 2008; Sanderson et al., 2013).) By contrast, Scotland was an early pioneer of public reporting in the UK (Mannion and Goddard, 2003; Marshall et al., 2003).

It is significant that cardiac surgery has been at the forefront of public reporting initiatives in the USA and UK. Some see it as a highly prestigious specialty of medicine (Katz, 1998; Creed et al., 2010) and yet is also open to greater measurability (compared to other specialties) (Harrison, 2002).

Descriptive accounts of public reporting are valuable but they also need to be explained conceptually. The case of cardiac surgery might be comparable but the framing and implementation of public reporting needs to be understood better, both now and in the future for other health systems. Here, we seek to do that by hypothesising whether two contrasting case studies might be converging towards a generic model of public reporting or diverging along separate lines. Convergence would indicate a form institutional isomorphism (Beckert, 2010) whereas divergence would point towards path dependency (Greener, 2005); a useful way to interpret this in terms of Scott's (2008) institutional pillars. This approach is consistent with wider institutional theory which posits institutions as the array of interests and ideas, norms and practices as well as formal structures and rules (Alvesson and Spicer, 2019). Scott's notion of institutional pillars is insightful as it argues that institutions comprise regulative, normative and cultural-cognitive elements, which Scott termed 'pillars' (Checkland et al., 2012; Muzio et al., 2013; Brunton, 2017). The pillars are not mutually exclusive; they interact together so that each shapes and is shaped by the behaviours by individuals and groups, at different institutional levels - at the clinical-patient interface, at organisational levels and at policy/institutional levels. The pillars are thus useful heuristic devices, transcending institutional boundaries. The regulative pillar refers to the espoused rules and sanctions of the institution, as pronounced in policy documents or legislation. The normative pillar comprises the standards and principles of institutional practices; this implies the expected duties and obligations of (say) surgeons in conducting their clinical practice. The cultural-cognitive pillar addresses the deeply seated assumptions and beliefs underlying actions; such 'symbolic systems' of the profession might, for example, confer reputational effect on public reporting (Shekelle et al., 2008). This framework can explain institutional patterns of change, especially those which are often portrayed as clashes between dominant and challenging logics, such as managerialism and professionalism (Ocasio et al., 2017). These pillars have the advantage of transcending the macro-meso-micro levels. They also help in comparative analyses.

\section{Methods}

The behavioural and policy responses to public reporting (in the form of mortality rates associated with individual named surgeons) are now examined empirically, drawing on data collected at the micro, meso and macro levels in the context of California and England. (This replicates Adler and Kwon's (2013) distinction between individual, organisation and institution, as well as the inter-connected nature of Scott's 'pillars' framework.) The micro level refers to surgeons' views and behaviour (Hannan et al., 1997; Barr et al., 2008); hospitals which provided cardiac surgery were either large, multi-specialty centres or (smaller) units dedicated to surgery. The meso level to managerial decision-making processes (Dranove et al., 2003); and the macro level to the external regulatory and policy environment (Gabe et al., 2012). This multi-level approach helps gauge the degree of enrolment and resistance to public reporting among surgeons, 
health care executives and health policy-makers, as well as the interactions between different levels and stakeholders in the health system. (Other studies have considered the impact of public reporting on outcomes; e.g. Bridgewater et al., 2007; Behrendt, and Groene, 2016.)

Two separate studies were conducted to investigate the responses to public reporting amongst institutional agents, their use of the data and consequences. The micro level of the English study involved one hospital and its local organisational and managerial setting (meso). The macro level comprised of the external regulatory and policy environment which would affect all similar hospitals. Data collection entailed (16) interviews with senior and junior surgeons, data analysts, (hospital and purchaser) managers, regulators and policy-makers (some of whom were surgeons). The interview sample was selected by virtues of their position, role and/or involvement in public reporting; this was identified by the head of surgery department (as a key informant), documentary evidence and observation. (Additionally, the English case study comprised of participant observation of surgeons in (10) morbidity and mortality (M\&M) meetings and in daily practice (over 2 days); given the comparative aspect of this paper, these data are not used here.) The USA study undertook a similar approach albeit in one state (California). It is hard to generalise across the diversity of the USA but California has previously proven to be a useful comparator of the UK or England (e.g. McDonald and Roland, 2009; Hussey et al., 2014). At the micro and meso levels, (10) interviews were held with practising surgeons in two hospitals, data analysts at the state level, regional purchasers and health service researchers. These individuals were identified with the aid of an academic researcher based in California, and documentary evidence. The two hospitals were selected because of the contrasting organisational status; one comprised of a large health plan and the other was an independent organisation. The macro level was different in that federal health policy has a different resonance in each state; therefore, macro level interviews were not undertaken. Instead, corroborative evidence from policy documentation and published research was garnered. Interviews in both case studies involved similar questions (Boxes 1 and 2); interview were semi-structured, allowing supplementary questions to probe answers in more depth. Interview questions were derived from a programme theory of public reporting (Exworthy et al., 2010), which sought to identify behavioural responses in terms of how public reporting should and does work in practice as well as the consequences (intended and otherwise) for different stakeholders. These formed the $a$ priori themes for subsequent analysis.

In both studies, patients were not included in the data collection because the focus of enquiry was upon professional and institutional responses to public reporting. Also, the resources available to both studies precluded the inclusion of patients. Even though evidence suggests a limited use of public reporting data by patients (Marshall et al., 2003; Fung et al., 2008), patient perspectives remain significant because they are liable to change in light of IT advances, previous patient behaviour and health system incentives. They are, however, beyond the scope of this paper.

All interviews (except for one) were audio-recorded (with permission) and transcribed. Interviews lasted 45-75 min. Contemporaneous, observational field notes were written in full. Analysis of interview transcripts and observational field notes was undertaken in a similar way for both studies; this involved researchers reading and coding transcripts initially before their widespread application. As the English case study was conducted before the Californian one (and despite the contextual differences), there were fewer discrepancies in the coding process for the latter. A software programme was not used to analyse transcripts given the relatively small sample size. The 'framework' approach guided the data search for commonalities and differences, thus identifying themes within and between different levels (Ritchie and Spencer, 1994; Gale et al., 2013). We drew descriptive inferences based on a priori and emergent themes before applying them to Scott's conceptual perspective. In what follows, we present our findings in terms of micro, meso and macro levels, each with sub-themes. Interviewee names have been anonymised.

A number of limitations are manifest in this comparative study. First, the complexity of the study (viz. two case studies, three levels of empirical data) militates against a more extensive 
Box 1. Interview schedule for California participants

1. Describe your job in relation to California Coronary Artery Bypass Graft Outcomes Reporting Program (CCORP)

2. What would you describe as the key aspects of CCORP which have been instrumental in its uptake by clinicians and organisations?

3. Would you like to see CCORP changed?

- Expanded, eliminated, refocused, new measures

4. How are your analyses of CCORP data being used beyond public reporting?

- E.g. Pay-for-performance, quality improvement, health plan designation of cardiac centres of excellence.

5. What other strategies are being used to manage surgical performance and improve it?

6. What might CCORP have achieved in the next 2 to 5 years?

7. Have you (or your organisation) encountered resistance by clinicians or hospitals to report data?

8. What have been the unintended consequences from CCORP?

9. What has been the impact of CCORP upon surgeons in training?

account within the scope of the journal. Second, a longitudinal study would have helped to gauge the ways in which public reporting has evolved. Some data offer a corroborative perspective but this is inevitably partial. Third, a more extensive data collection could have given a more rounded assessment. More staff (e.g. nurses) and patients could have been interviewed but the focus of both case studies was on the changing nature of medical professionalism. More observational data would also have provided more depth of insight. These factors illustrate the limitations of the study and also highlight areas of future research.

\section{Results}

\subsection{Micro level}

In both studies, some surgeons opposed the ways in which surgery is measured and data were attributed to named individual surgeons. Initially, they did so in a mix of passive and active resistance, especially where individual/organisational reputation was at stake; this has become more muted over time. In England, all respondents noted that some surgeons remained resistant to public reporting although others surgeons were more accepting, as illustrated by Derek and Ralph.

'There are quite a few dissenting voices yeah, quite a few, the laggards for want of a better word, decent people...' (Derek, surgeon and regulator, England).

'There's also an aspect to which having the results published has been cathartic and we've done it, we've been there, you know. Any fall out has happened, we've done it over a number of years now and I think people are quite relaxed about it' (Ralph, surgeon, England).

Public reporting had even prompted resistance in the form of resignations from the surgeons' professional body.

'This whole issue has been quite controversial and in some areas, some members have actually resigned from the Society' (Larry, surgeon and professional leader, England).

Similar resistance and resentment to public reporting were also apparent in California.

'Surgeons have been resistant to measurement' (Arthur, researcher, California).

Resistance concerned the unit of analysis in both forms of public reporting. Naming of individual surgeons within specific hospitals, it was argued, gave misleading inferences about team-based care. 
Box 2. Interview schedule for England participants

1. How was poor surgical performance monitored before (personally and within the profession, their experience)?

2. What has been your role in implementing public reporting (locally/nationally)?

3. What discussions with colleagues took place locally about public reporting?

4. What were staff concerns about implementing public reporting?

5. Has there been any resistance to public reporting?

6. What has been the impact of public reporting upon relationships with staff, with managers, with external agencies?

7. How has public reporting affected surgical work?

'There's a lot of push-back [by surgeons to public reporting] which we are philosophically sympathetic to because if you really believe in team care and integrated care and co-ordination - all that stuff, picking individual physician as a unit of analysis is kind of silly' (Daniel, purchaser, California).

However, Californian respondents thought practicing surgeons had become more accepting of public reporting over time. This might be gauged by the falling numbers of appeals made to the state-wide body overseeing the public reporting.

'So we've been through it [appeals by surgeons] three times and it's [numbers appealing] gone down each time. The first time we probably had about in the twenties. We learned a lot. People were appealing things that it affected their ratings ... and the next time it was less and then this last time which was two years ago, we just had a handful' (Hannah, data analyst, California).

A central concern at the micro level was whether public reporting was voluntary or mandatory. Public reporting schemes have mostly shifted from voluntary to mandatory disclosure. In California, public reporting (California Mortality Reporting Program; CMRP) was initially voluntary at the hospital level (Parker and Damberg, 2005).

'About 25 to 30\% of hospitals did not participate but this was largely because they were not STS [Society for Thoracic Surgeons] members and did not have to computer software to enable them to report mortality data' (Jack, data analyst, California).

However, by 2005 report, non-participation was 36\% (Parker and Damberg, 2005: 3). In the early-mid 2000s, coronary artery bypass graft (CABG) reporting in California became compulsory (California CABG Outcomes Reporting Program; CCORP) with the passage of legislation (Senate Bill 898 in 2001) (Lee and Carlisle quoted in Parker and Damberg, 2005: v). The concern that public reporting would be mandated (and thus introduce greater regulation of surgeons) had been recognised at the outset.

'I know when I was in New York, in the mid '80s going to early '90s that the whole discussion was even the validity of a database, the participation of a database and one of the main attacks on having this database that it would be eventually used as a policing' (Henry, surgeon, California).

In England, voluntary participation has been prized by the surgical specialty which secured surgeons' participation as public reporting moved from an internal educational exercise to external audiences (Exworthy, 1998; Keogh et al., 2004). According to two English respondents, about 
one-sixth of cardiac surgeons did not disclose their mortality rates in the 2000s. Indeed, as one English respondent commented:

'[The regulator] never ever said that publication of individual surgeon's results should be mandatory' (Barry, surgeon and policy-maker, England).

The fear expressed by most English surgeons was that reporting would become mandatory and linked to more explicit control of their practice, with a loss of clinical autonomy.

'I think these things [public reporting] are very good when used internally and professionally. However, when these figures go in the so-called public domain, I think this is where I feel a little bit uncomfortable with, because then... the data needs a lot of knowledge to interpret it, to understand it' (Tim, junior surgeon, England).

By 2013, the re-launch of public reporting in 10 specialties referred to a high(er) degree of participation in England. Regarding this initiative, Bridgewater (2013) cites legal advice, indicating that individual results should not be published without individual surgeons' consent. However, he claims that data about non-participating doctors will be relayed to local executives and purchasers but not to the public. He, nonetheless, reassures that consent rates are 'more than 96\%'; hence, non-participation appeared to have to fallen to $4 \%$.

The use of publicly reported data by patients in their decision-making varied by circumstance and context between England and California. In both case studies, surgeons commonly stated that patients did not use the data.

'My experience is that very few patients tend to come and want to discuss the results or discuss the stuff on the website' (Rupert, surgeon, England).

'Public reporting has not, in my mind in the last 5 years, has not really affected patient behavior and it hasn't really affected cardiology referring. ... Over the last 5 years,... one of the things that we worried about... is that when we share this data, patients aren't going to come and see me. That's not borne out. Cardiologists don't see this data. I mean they see it but send the patient. Their human behavior is that they know that the high risk and they continue to send [patients] to you' (Henry, surgeon, California).

These views corroborate the conclusions of Marshall et al. (2003) and Shekelle et al. (2008) in reviews of extant evidence, mainly from the USA. (This would also explain the apparent 'failure' of naming and shaming schemes in England; Bevan et al., 2019.) However, the reasons diverge. The English policy of 'patient choice' (which encouraged patients to select between 'competing' hospitals) had a mixed uptake (Greener, 2003; Fotaki, 2006). Moreover, cardiac surgery is a tertiary service and requires referral from a cardiologist, so patient choice is less relevant (and another reason for their exclusion from this study). In California, patients' decision-making is heavily mediated by the institutional rules of their health insurers. Jerry described one patient from a nearby town who wanted to be treated at his facility.

'Their insurance won't pay for it. So the people are trapped by their insurances much more so in the State of California than any other state. So a great example is [the town's] hospital that has a very low [volume of patients]... and even if they wanted to leave there, the majority of patients in that area can't leave. They're trapped by their insurance' (Jerry, surgeon, California). 
Although the 'exit' strategy was less available (compared to the voice and loyalty strategies) (Hirschman, 1970) in California and England, there are signs of patients becoming less reliant on traditional sources of information about clinical performance (Tritter, 2009).

' $25 \%$ of patients that I did last year came to me independent of their primary care doctors or their cardiologists' recommendation. Well, it was 90\% just a decade ago' (Jerry, surgeon, California).

It had been feared that public reporting might dissuade surgeons from operating on high risk patients, afraid that their reported outcomes would be 'worse'. However, although recognising that risk-taking was inherent in surgery, English and Californian surgeons presented a narrative which balanced clinical need against low trust in the data.

'It [treating a high risk patient] would affect my published performance number, so yeah, so it would just make me unhappy. But it would not stop me doing it, and the reason I say it is because of the risk algorithms we have are relatively poor' (Damon, surgeon, England).

'Some surgeons, probably younger ones, are keeping track of how they're doing. They are probably maybe less willing to take on a patient if they think it's going to push them into a poor performance category... There is avoidance of certain patients and it's more subtle than the data can turn out' (Jack, data analyst, California).

This reasoning moderates any reputation effect of public reporting because the surgeon's peers would tacitly acknowledge the limitations of algorithms of case-mix adjustments. This might invoke the notion of equality of competence in a contemporary form (Causer and Exworthy, 1999).

\subsection{Meso level}

In England, hospital executives reported that public reporting was loosely connected to organisational imperatives such as quality improvement or cost control. Executives seemed initially content to allow surgeons to develop their own professionally-led initiatives.

'We've [hospital administration] tended to dip in and out of things ... So we've done mortality in isolation and we've looked at rates of complaints or something. We've never quite brought the whole thing together to really use it to help improve what we're doing rather than just measure non-compliance [of public reporting]' (Dave, senior executive, England).

Executives noted the need for greater transparency and that this could be advantageous to their organisation in future. Although such comments may have over-stated the impact of public reporting, it does signal the thinking of executives in how these data could be used.

'I know that when [former chief executive officer of the case-study hospital] - his view was that we should publish it [data] because in the world of the Foundation Trusts [i.e. more autonomous NHS organisations] and free [patient] choice, extended choice, you know, to be that hospital which is open and honest about its mortality rates, even if the public actually probably don't understand [the data], it gives the sense of this is a hospital with nothing to hide' (Ralph, surgeon, England).

More recently, public reporting has seemingly stimulated efforts within organisations to improve quality, a process which was probably more advanced in California than England, according to respondents. This was a recognition that the focus of public reporting was shifting towards health care systems and away from individual surgeons. 
'I'm not a fan of individual surgeon [level reporting]; I think it is clinical teams. And the other point I wanted to make... when organisations fail, 99 times out of a 100 it's managerial, it isn't clinical' (Barry, surgeon and policy-maker, England).

'I think the fundamental issue ... I think almost always the problem is not the person, it's the system that let the person down and ... that's what we concentrate on. We don't try to sling blame. We try to concentrate on trying to improve the system ... to make it possible for a person, any person to succeed. I always say that you could put anybody in my job right here right now and they would succeed without a question' (Jerry, surgeon, California).

Bevan et al. (2019) argue a similar point by suggesting that trust and altruism are suitable for improvements sought at an individual level but ill-suited for systemic improvements.

By contrast, the Californian hospitals in this study were using publicly reported data in aid of quality improvement and service re-organisation. The initial 'loose coupling' between hospital executives and surgeons was now becoming more integrated (Kitchener et al., 2005). This coupling challenged the viability of surgical programmes with a low volume of surgery, for example.

'One mortality at a small programme [hospital] can make you bad and they think it's going to be a punitive measure rather than just trying to elevate their entire programme' (Jerry, surgeon, California).

Jerry cited examples where 'those [surgical] programmes were really forced to close' as a result of public reporting. He claimed that 'most of the programmes they need to be closed are closed already' meaning that the focus was shifting towards quality improvement, rather than removing low volume centres. Surgeons recognised the influence of organisational systems upon their surgical practice and public reporting. One chief surgeon explained this regarding his and another hospital within the local area where he worked.

'We're in a very similar healthcare model, which is a capitated, integrated management system, not only from physicians but with hospital... We're comparing similar patients ..., we have similar electronic records... It makes more sense to compare data and our outcomes in that way as opposed to us comparing to [another local, independent hospital]. How can you compare and then come to any reasonable conclusions because their population's different, their machines are different, their technology's different and so their products will be different. Their outcomes will be different' (Henry, surgeon, California).

However, other Californian hospitals did not work this way. Another surgeon explained the consequences of the different hospital system in which he worked:

' $25 \%$ of my patients have no insurance and now for the [Californian] state that's true, for heart surgery. [Hospital X] has zero, so it's a completely different model... No homeless person ever goes to [hospital X]. They have been trained to go to [public hospital Y]. So it was $18 \%$ in 2010 for [public hospital Y] of cardiac surgery which was not reimbursed at all... If you don't have insurance, the chance that you're going to need, you know, for the first 30 days - the care is rehab facilities, visiting nurses, all those don't exist for $18 \%$ of the patients at [public hospital Y]. [Public hospital Y] has to eat it' (Jerry, surgeon, California).

Note that each surgeon highlighted different aspects. Henry noted the benefits of an integrated system while Jerry pointed to its impacts of exclusionary approaches.

Linking reimbursement claims data to public reporting had generated controversy in California. According to one respondent, one such initiative in 2008 had created a huge firestorm of opposition and conflict within the state' and had led to 'law suits and litigation and political 
stuff that was very debilitating for everybody' (Daniel, purchaser, California). In the USA, such financial incentives have arguably been more extensively developed than in England (Rosenthal and Dudley, 2007; Farrar et al., 2009; McDonald and Roland, 2009) which have generated some resistance amongst surgeons.

'If there's... money attached to it, or referrals or some other financial impact, then there's going to be a lot more contention about how my named data appears on the ranking' (Daniel, purchaser, California).

There had been similar pressures (and some progress) to link publicly reported data to reimbursement at a system or organisational level. Note, for example, Dave's comment (see above) about 'doing mortality in isolation' or the English initiative linking quality improvement to additional financial reimbursement, called CQUINs (commissioning for quality and innovation) (Murray, 2017). However, in the past few years, emphasis has been on financial constraints associated with austerity (Charlesworth et al., 2016).

In both case studies, hybrid 'surgeon-executives' helped to broker the interests of surgeons and the wider institutional context.

\subsection{Macro level}

At this systemic level, we examine the role of the profession, the impact of the media and the salience of mortality as the publicly-reported measure.

First, the surgical profession was instrumental in promoting the introduction of publicly reported surgical data in England but less so in California. In England, some of the former leaders of the profession have become senior figures in the health ministry (Department of Health) and the health care regulator (Care Quality Commission). Their professional interest in and development of surgical audit in the 1990s transferred to a wider audience initially in cardiac surgery in the 2000s and subsequently to other specialties (from 2013). These English surgical leaders sought to accommodate external pressures (such as patient choice and competition) with the specialty's members' interests. However, this accommodation had strained the cohesion of the specialty. The leaders (who were supportive of public reporting) tried to maintain collegiality with surgeons (some of whom were resistant).

'I don't draw a distinction between myself and my colleagues. I am still a surgeon I am not a... bureaucrat' (Barry, surgeon and policy-maker, England).

Another English senior surgeon recognised the need to foster public reporting while stressing the continued need for professional ownership of it.

'So we have to have some sort of measurement and far better that we do it and do it professionally and well, than have it imposed on us ... I suppose some people would feel it's being imposed on us but ...I would reject that. I think we are still leading the way with it and we get other people to help us with it... I know there's a bit of resentment, certainly amongst our members, that we're scrutinising ourselves so closely and indeed, being scrutinised from outside' (emphasis added) (Larry, surgeon and professional leader, England).

Decisions about the form and scope of public reporting had involved the surgical specialty which enabled it to retain significant control.

'I do very much agree with a point that performance needs to be monitored, because without monitoring of performance... then you don't really have an accurate idea as to where you're 
going, whether you're going through a difficult period, a bad patch' (Ikram, junior surgeon, England)

However, the surgical profession in California was much less involved in the inception of public reporting. Unlike England, it was not the Californian surgical profession which engaged initially but rather the California Medical Association and the cardiologists.

'Now at that point they [the Californian state] had to engage the professional communities. Interestingly they did not go to the Society of Thoracic Surgeons; they went to the ... California Chapter of the American College of Cardiology who in some ways are their competitors, right, and they went to the California Medical Association' (Jack, data analyst, California).

Respondents noted that Californian cardiac surgeons were less cohesive as a profession and did not engage with the state-led initiative into public reporting. The surgeons did subsequently become more involved. Respondents in California suggested that the state's public reporting has been prompted by experience elsewhere in the USA rather than a surgeon-led initiative. One recounted how a purchaser in the state instigated public reporting.

'They [purchasers] said back in the- the 90s- 95 or 96 so, this sort of thing 'New York's been doing it successfully. We're a huge state, there's a lot of people here getting bypass surgery in California. We should be-you know the west coast should be able to do what the east has done', and so they put some money, you know, into that argument' (Jack, data analyst, California).

Indeed, the larger states (such as New York or California) have had the resources and capability to undertake programmes of public reporting unlike smaller states.

Second, the role of the media, often using freedom of information, has been instrumental in introducing public reporting. In New York State, for example, Newsday magazine published hospital data while in England, the Guardian newspaper adopted a similar approach (Hannan et al., 1994; Keogh et al., 2004). Media-led public reporting seemed to accelerate developments; indeed, one respondent explained that surgeon-led initiatives were over-taken by the Guardian's strategy:

'We were boxed into it [public reporting]...we were into trying to get good measurements of results for individual units; what then happened was we were subject to a freedom of information act request from the Guardian' (Barry, surgeon, England).

However, in California, the impetus for public reporting was driven less by any particular media concern (as in New York). Initial interest there was sparked by a purchaser group (Pacific Business Group on Health; PBGH) who, in 1995, collaborated with the State-wide office for health planning. The Californian media were initially interested but since then, however, the urgency of public reporting for them has waned over the years. One respondent 'measured' the decline in interest by column inches in the newspaper:

'We ... issued this report in April and we had - how many press calls? Even with a brand new measure in here [in the report] which we kind of think, 'Oh we'll add another- another outcome measure' - keep it fresh, and we have less press calls than we ever had' (Hannah, data analyst, California). 
'My last interview was when the last report came out ... I gave an interview to [local newspaper], you know - page 10, small paragraph. You know the newspapers are done with this topic. So it's not getting any publicity per se. It should be news but it's not. The people are burnt out from it, they hear the data all the time, they're burnt out from it' (Jerry, surgeon, California).

The 'light' of transparency, shone by the media, may not necessarily generate continuing improvements in health care quality (cf. Tsoukas, 1997). Even over a decade ago, Chassin (2002) claimed that 'press coverage, so copious at the outset of the programme, is waning. A Lexis-Nexis search in April 2002 revealed no newspaper reports on the most recent public release of CSRS [cardiac surgery reporting system] data in January 2001' (p. 49) (cf. Huesch et al., 2014).

Third, common to both case studies was the measure of mortality rates for named individual surgeons working within specific hospitals. In England, the (30 day post-operative) mortality rate for CABG (the main surgical procedure) was $1.6 \%$ in the 40 UK surgical centres (2008-2009) (http://heartsurgery.cqc.org.uk/Survival.aspx). In California, the 'observed mortality rate' for 'isolated CABGs' (involving no other procedure) by hospital was $2.24 \%$ in 120 hospitals (undertaking CABG surgery) (2007-2008) (http://www.oshpd.ca.gov/HID/Products/Clinical_Data/CABG/0708Breakdown.html). Such rates have been falling before and since public reporting. However, it was the use of the rate and its symbolic value which were significant here.

'Mortality rates are really for the bad apples' (Craig, surgeon, England).

'The surgeon has a responsibility to the programme to say, 'Well, you know, if we chuck up all these high mortalities and let you go, then we may be fined or shut down or penalised' (Henry, surgeon, California).

The 30 day period of measurement was problematic since, in some hospitals, patients were discharged without adequate means of care at home.

'Why we're using operative mortality as the only indicator of publicly reported to me is a complete mystery' (Daniel, purchaser, California).

In California, the mandated use of the 'isolated CABG' mortality rate has, some respondents claimed, caused difficulties. Reductions in mortality rates and a decline in the number of CABG procedures meant this was a less relevant measure.

'One thing that has kind of maybe pushed this a little more into the spotlight is just recently the in-hospital mortality rate for PCI [percutaneous coronary intervention, or angioplasty] has inched above the in-hospital mortality rate for isolated CABG' (Hannah, data analyst, California).

'With deep sternal wound infection, it's measured over a 30-day period so somebody may be discharged 5 days after surgery but the surgeon is still responsible for their patient for the 25 days post discharge and during that period of time they, you know, the patient's ability to manage their wound effectively is compromised' (Eric, quality improvement facilitator, USA).

'We're down the 1-2\% range [of mortality]. It doesn't discriminate performance of the variable that people are concerned about when they undertake the treatment' (Daniel, purchaser, California).

English surgeons echoed concerns with mortality as a performance measure. However, despite these concerns, they too continued to use it. 
'I think it's [mortality rate] not a panacea that some of its advocates would suggest... Mortality's often inappropriate because it's just not very discriminatory you know, when things are low... but in a lot of cases, yes, you'll have a 1 or $2 \%$ mortality rate... Actually what does it tell you if somebody's got a $10 \%$ mortality rate. That's all it just tells you' (Ralph, surgeon, England).

\section{Discussion}

By comparing the behavioural responses of stakeholders at micro, meso and macro levels in case studies of public reporting in California and England, it has been possible to discern the extent to which these two health systems have been converging. Patterns of convergence were evident (around measurement and the use of data) but equally, strong differences persisted (especially regarding professional and institutional interests). In each case, the interaction between ideas and interests of institutions and individuals generated the observed outcomes. Beyond description, these findings require explanation; Scott's (2008) pillars framework is thus instructive here.

The regulative pillar contrasts the legislative approach of California (which mandated state reporting of surgical mortality) with the (initially) professionally-led strategy in England. These approaches somewhat constrained health systems from moving over time towards more relevant measures of surgical performance. Californian public reporting had also been initiated by purchasers' concerns for the comparative value of health care spending between providers whereas purchasers (commissioners) in England had taken a much more detached role, preferring instead to allow health care providers (i.e. hospitals) to manage the process. In the English case study, the medical profession was largely in control of how performance was measured and the data were used.

Sanctions for 'poor' performance were apparent mainly in California with purchasers removing low volume, poor quality providers. Fewer explicit sanctions were evident in England. However, the incentives for 'outstanding' performance were much less distinct, as public reporting often was primarily concerned with 'moving performance from awful to adequate' (Bevan et al., 2019). Regulators and policy-makers in both cases were seeking to address similar challenges of health system performance and were increasingly using public reporting to do so. Public reporting had become a normative doctrine in both case studies. Although other measures (such as financial control) were used to address these challenges (especially in England), public reporting offered a seemingly robust and easily comparable performance measure (namely, mortality). However, in both cases, data quality undermined the ability to manage surgical performance, at least initially. Moreover, the salience of public reporting has lessened as mortality rates have improved over time (thereby reducing variations between the 'best' and 'worst' surgeons, and emphasising further need to consider other measures such as patient experience). As a result, public and media interest has waned. California's earlier experience of public reporting offers a dynamic picture of public reporting over time and thus offers a perspective upon the trajectory of public reporting in England. Some convergence had taken place but distinct differences remained.

Regarding the normative pillar, the institutional imperative to public reporting appeared strong in both cases (especially as surgeons' participation became mandatory in both cases). In California, the institutional pressure came from the State and the purchaser group, with surgeons playing a minor role in framing the scope and remit of public reporting. Yet, once introduced, surgeons were involved in public reporting as a means towards improving the quality of services. In England, surgeons' leaders recognised the need to foster ownership of public reporting; surgical leaders in the specialty and in policy-making were crucial mediators between surgeons and institutional interests. These leaders facilitated the introduction of public reporting. Although such approaches might indicate an awareness among the medical profession of the potential for greater external control, they do also denote a re-professionalisation of medicine which sought to reset the 
position and status of surgeons vis-à-vis other stakeholders. Such re-professionalisation was marked by the emphasis on accountability (redolent of managerialism) and new forms of engagement with patients (qua consumers) (Elston, 2009). Regarding the first of these, health care executives were connecting public reporting with institutional imperatives (such as pay-for-performance) but the use of such data in quality improvement was variable. This was more prevalent in California than England. Second, the use of these data by patients was hardly apparent in either case study. Patients rarely used the data and the public voice featured little. Media reports took increasingly scant notice of the data. This may be exacerbated by the esoteric measure of surgical performance (i.e. adjustment of mortality rates according to high risk patients) and whose dissemination is often opaque (Hildon et al., 2012). Suddaby and Viale (2011) argued that although the profession has sometimes been instrumental in devising and disseminating measures of 'their' members' performance, often for reasons of public interest, such measures tended to be understood largely only by the professionals themselves. Moreover, the partial use of publicly reported data may help explain behavioural responses which underlined the 'reputation pathway' as being likely to generate most improvement in mortality rates (Hibbard et al., 2003), as opposed to a selection (by patients) pathway.

As for the cultural-cognitive pillar, the 'transparency doctrine' appeared relentless in both cases. Initial resistance to public reporting by surgeons had been evident in both cases but this was declining. Evidence presented here showed hardly any overt resistance to the notion of transparency by surgeons. This reflected a shift in which participation had initially been voluntary but had become mandatory. In some ways, this might increase the incentive for gaming (e.g. avoiding high risk patients) if there were more explicit penalties for 'poor' performance (Smith, 1995). Moreover, most surgeons and their professional leaders in both cases sought to incorporate public reporting into their norms of professionalism (e.g. as a tool of quality improvement) and thereby deflect possible external threats to their autonomy. Although public reporting did enrol most surgeons, participation was sometimes begrudging; minimal resistance was thus apparent (Westaby, 2014). If done begrudgingly, this suggests that public reporting did not fully match surgeons' own professional logics (i.e. autonomy and self-interest). As public reporting in England had been pioneered by the surgeon's own professional body, this dissonance was perhaps less marked in England compared with California. In any case, it appeared to be leading towards a greater re-stratification within the profession between the knowledge elite (generating the evidence and devising case-mix adjustments), the administrative elite (applying the doctrine of public reporting in terms of incentive regimes) and rank-and-file surgeons (who were the object of and subject to public reporting) (Miller, 1992; Freidson, 1994).

Overall, although public reporting was implemented in different ways at different time points, there were some signs of apparent convergence in the process and outcomes of public reporting in both cases. Surgeons in both cases were increasingly aligned with the institutional aims and practice of public reporting. It had become not only a 'system logic' (Tuohy, 1999) but possibly also an 'electronic panopticon', providing continuous surveillance of surgeons' performance (Bain and Taylor, 2000; Exworthy, 2015); this strategy might be effective than overt cost control. Yet, there were also signs of divergence or perhaps more strictly path dependence (Greener, 2002) which reinforced distinctions, both geographically between cases and temporally with the status quo ante. This was perhaps most evidence in the regulatory pillar. For example, the longer period of implementation in California, together with stronger organisational incentives, had perhaps led to an approach which integrated public reporting more closely with organisational system and processes. The evidence from the English case study suggested this integration was still nascent. This might reflect the sense in which external agents (in the English case) were more hesitant in challenging surgeon's (poor) performance and/or the strength of professional control in the nature and content of public reporting.

In summary, the 'pillars framework' is a useful heuristic device to demonstrate how the behavioural and policy responses to public reporting by health system stakeholders are shaped by the nature of public reporting and the context into which it is implemented. The responses also 
shaped dynamically by subsequent iterations of public reporting, most evidently in California. These interactions between cardiac surgeons, organisational interests and health system imperatives show the far-reaching effects that public reporting has had and continues to have. As a result, on-going divergence persists despite pressure for greater convergence.

\section{Conclusion}

Public reporting is likely to remain an important aspect of all health systems but will be shaped by a health system's own imperative and approach to transparency. Despite strong imperatives towards convergence, the context of each health system matters. Analyses need therefore to be sensitive to the context-specific factors of each system in framing the interaction between their regulatory, normative and cultural factors. These factors will both shape and are shaped by actors' decisions and behaviours. This interaction will also be framed by the extent of policy learning between health systems. Specifically, the American approach to public reporting has been instrumental to approaches in England. Although international comparative studies (such as this) help illuminate the impact of such intersections (Dolowitz et al., 1999), policy learning will also reflect the ways in which actors 'piece together' various aspects of information and experience into their system-specific approach (Freeman, 2007).

Although greater transparency is a laudable objective for any health system, it is not clear that public reporting will necessarily be as effective as its proponents intended. Alone, it will not act as sufficient stimulus to restore trust in and reputations of the medical profession, to enable to patient decision-making, or to enable quality improvement. Indeed, the growing need for cost savings in all health systems may lessen the salience and impact of public reporting. Yet, public reporting is re-shaping the surgical profession itself and the relations between surgeons and their organisations, and their patients.

Acknowledgements. The 'English' study was funded by the ESRC (RES-153-25-0100); we are grateful to them for their funding. The 'California' study was made possible with help from staff from the Institute of Health Policy Studies, University of California San Francisco (UCSF). We thank all the research participants in this study. An earlier version of the paper was presented at the American Sociological Association conference. We are grateful to the Editors and reviewers of Health Economics, Policy and Law for their continued support of this paper and the constructive comments.

\section{References}

Adler P and Kwon SW (2013) The mutation of professionalism as a contested diffusion process: clinical guidelines as carriers of institutional change in medicine. Journal of Management Studies 50, 930-962.

Alvesson M and Spicer A (2019) Neo-institutional theory and organization studies: a mid-life crisis?'. Organization Studies 40, 199-218.

Bain P and Taylor P (2000) Entrapped by the 'electronic panopticon'? Worker resistance in the call centre. New Technology, Work and Employment 15, 2-18.

Barr JK, Bernard SL, Sofaer S, Giannotti TE, Lenfestey NF and Miranda DJ (2008) Physicians' views on public reporting of hospital quality data. Medical Care Research and Review 65, 655-673.

Beckert J (2010) Institutional isomorphism revisited: convergence and divergence in institutional change. Sociological Theory 28, 150-166.

Behrendt K and Groene O (2016) Mechanisms and effects of public reporting of surgeon outcomes: a systematic review of the literature. Health Policy 120, 1151-1161.

Bevan G and Fasolo B (2013) Models of governance of public services: empirical and behavioural analysis of econs and humans. Chapter 2. In Oliver A (ed.), Behavioural Public Policy. Cambridge: Cambridge University Press, pp. 32-68.

Bevan G, Evans A and Nuti S (2019) Reputations count: why benchmarking performance is improving health care across the world. Health Economics, Policy and Law 14, 141-161.

Blomgren M (2007) The drive for transparency: organizational field transformations in Swedish health care. Public Administration 85, 67-82.

Bridgewater B (2013) Consultant-level outcomes reporting: the facts about consent. 13 June 2013. Available at http://hqip. org.uk/consultant-level-outcomes-reporting-the-facts-about-consent/.

Bridgewater B, Grayson AD, Brooks N, Grotte G, Fabri BM, Au J, Hooper T, Jones M and Keogh B (2007) Has the publication of cardiac surgery outcome data been associated with changes in practice in northwest England: an analysis of 25 730 patients undergoing CABG surgery under 30 surgeons over eight years. Heart (British Cardiac Society) 93, 744-748. 
Brunton M (2017) Risking the sustainability of the public health system: ethical conundrums and ideologically embedded reform. Journal of Business Ethics 142, 719-734.

Calnan M and Rowe R (2008) Trust Matters in Health Care. Maidenhead: Open University Press.

Causer G and Exworthy M (1999) Professionals as managers across the public sector. In Exworthy M and Halford S (eds), Professionals and the new Managerialism in the Public Sector. Buckingham: Open University Press, pp. 83-101.

Charlesworth A, Roberts A and Lafond S (2016) NHS Finances under the coalition. Chapter 3. In Exworthy M, Mannion R and Powell M (eds), Dismantling the NHS? Evaluating the Impact of Health Reforms. Bristol: Policy Press, pp. 39-64.

Chassin MR (2002) Achieving and sustaining improved quality; lessons from New York state and cardiac surgery. Health Affairs 21, 40-51.

Checkland K, Harrison S, Snow S, McDermott I and Coleman A (2012) Commissioning in the English National Health Service: what's the problem?'. Journal of Social Policy 41, 533-550.

Clarke S and Oakley J (eds) (2007) Informed Consent and Clinician Accountability: The Ethics of Report Cards on Surgeon Performance. Cambridge: Cambridge University Press.

Creed PA, Searle J and Rogers ME (2010) Medical specialty prestige and lifestyle preferences for medical students. Social Science and Medicine 71, 1084-1088.

Davis K, Collins KS, Schoen C and Morris C (1995) Choice matters: enrollees' views of their health plans. Health Affairs 14, 99-112.

Dixon-Woods M, Yeung K and Bosk CL (2011) Why is UK medicine no longer a self-regulating profession? The role of scandals involving 'bad apple' doctors. Social Science and Medicine 73, 1452-1459.

Dolowitz DP, Hulme R, Nellis M and O’Neill F (1999) Policy Transfer and British Social Policy. Buckingham: Open University Press.

Dranove D, Kessler D, McClellan M and Satterthwaite M (2003) Is more information better? The effects of 'report cards' on health care providers. Journal of Political Economy 111, 555-588.

Elston M-A (2009) Re-making a trustworthy medical profession in twenty-first century Britain. In Gabe J and Calnan M (eds), The New Sociology of the Health Service. London: Routledge, pp. 17-36.

Exworthy M (1998) Clinical audit in the NHS internal market: from peer review to external monitoring. Public Policy and Administration 13, 40-53.

Exworthy M (2015) The iron cage and the gaze: interpreting medical control in the English health system. Professions and Professionalism 5. doi: https://journals.hioa.no/index.php/pp/article/view/944

Exworthy M and Freeman R (2009) The United Kingdom: health policy learning in the NHS. In Marmor TR, Freeman R and Okma KGH (eds), Comparative Studies and the Politics of Modern Medical Care. New Haven, CT: Yale University Press, Chap. 6, pp. 153-179.

Exworthy M, Bindman A, Davies HTO and Washington AE (2006) Evidence into policy and practice? Measuring the progress of policies to tackle health disparities and inequalities in the US and UK. Milbank Quarterly 84, 75-109.

Exworthy M, Smith G, Gabe J and Jones IR (2010) Open heart surgery? The whys and wherefores of disclosing clinical performance data. Journal of Health, Organization and Management (special issue: medical regulation) 24, 571-583.

Farrar S, Yi D, Sutton M, Chalkley M, Sussex J and Scott A (2009) Has payment by results affected the way that English hospitals provide care? Difference-in-differences analysis. British Medical Journal 339, b.3047.

Feachem RGA, Sekhri NK and White KL (2002) Getting more for their dollar: a comparison of the NHS with California's Kaiser Permanente. British Medical Journal 324, 135-141.

Fotaki M (2006) Choice is yours: a psychodynamic exploration of health policymaking and its consequences for the English National Health Service. Human Relations 59, 1711-1744.

Freeman R (2007) Epistemological bricolage: how practitioners make sense of learning. Administration and Society 39, $476-496$.

Freidson E (1994) Professionalism: The Third Logic. Chicago: University of Chicago Press.

Fung CH, Lim Y-W, Damberg C and Shekelle PG (2008) Systematic review: the evidence that publishing patient care performance data improves quality of care. Annals of Internal Medicine 148, 111-123.

Gabe J, Exworthy M, Jones IR and Smith G (2012) Towards a Sociology of Disclosure: the case of surgical performance. Sociology Compass 6, 908-922.

Gale NK, Heath G, Cameron E, Rashid S and Redwood S (2013) Using the framework method for the analysis of qualitative data in multi-disciplinary health research. BMC Medical Research Methodology 13, 117.

Gray JAM (2011) How to Get Better Value Healthcare. London: Offox Press.

Greener I (2002) Understanding NHS Reform: the policy-transfer, social learning, and path-dependency perspectives. Governance 15, 161-183.

Greener I (2003) Patient choice in the NHS: the view from economic sociology. Social Theory and Health 1, 72-89.

Greener I (2005) The potential of path dependence in political studies. Politics 25, 62-72.

Greer S (2008) Devolution and divergence in UK health policies. British Medical Journal 337, a2616.

Ham C (2005) Lost in translation? Health systems in the US and the UK. Social Policy and Administration 39, $192-209$.

Hannan EL, Kilburn H, Racz M, Shields E and Chassin MR (1994) Improving the outcomes of coronary artery bypass surgery in New York state. Journal of American Medical Association 271, 761-766. 
Hannan EL, Stone CC, Biddle TL and DeBuono BA (1997) Public release of cardiac surgery outcomes data in New York: what do New York state cardiologists think of it?. American Heart Journal 134, 55-61.

Harrison S (2002) New labour, modernisation and the medical labour process. Journal of Social Policy 31, 465-485.

Hibbard JH (2008) What can we say about the impact of public reporting? Inconsistent execution yields variable results. Annals of Internal Medicine 148, 160-161.

Hibbard JH, Stockard J and Tusler M (2003) Does publishing hospital performance stimulate quality improvements. Health Affairs 22, 84-94.

Hildon Z, Allwood D and Black N (2012) Impact of format an content of visual display of data on comprehension, choice and preference: a systematic review. International Journal for Quality in Health Care 24, 55-64.

Hirschman AO (1970) Exit, Voice and Loyalty: Responses to Decline in Firms, Organizations and States. Boston: Harvard University Press.

Hood C (2007) What happens when transparency meets blame-avoidance?. Public Management Review 9, 191-210.

Huesch MD, Currid-Halkett E and Doctor JN (2014) Public hospital quality report awareness: evidence from National and Californian Internet searches and social media mentions, 2012. BMJ Open 4, e004417.

Hussey PS, Luft HS and McNamara P (2014) Public reporting of provider performance at a crossroads in the United States: summary of current barriers and recommendations on how to move forward. Medical Care Research and Review 71, 5S-16S.

Jeacle I and Carter C (2011) In TripAdvisor we trust: rankings, calculative regimes and abstract systems. Accounting, Organizations and Society 36, 293-309.

Katz P (1998) The Scalpel's Edge: The Culture of Surgeons. Boston, MA: Allyn and Bacon.

Keogh B, Spiegelhalter D, Bailey A, Roxburgh J, Magee P and Hilton C (2004) The legacy of Bristol: public disclosure of individual surgeons' results. British Medical Journal 329, 450-454.

Kitchener M, Caronna C and Shortell S (2005) From the doctors' workshop to the iron cage? Evolving models of physician control in US health systems. Social Science and Medicine 60, 1311-1322.

Kraska RA, Krummenauer F and Geraedts M (2016) Impact of public reporting on the quality of hospital care in Germany: a controlled before-after analysis based on secondary data. Health Policy 120, 770-779.

Levay C and Waks C (2009) Professions and the pursuit of transparency in healthcare: two cases of soft autonomy. Organization Studies 30, 509-527.

Llewellyn S (2001) Two-way windows: clinicians as medical managers. Organization Studies 22, 593-623.

Lynn LE (1998) The new public management: how to transform a theme into a legacy. Public Administration Review 58, $231-237$.

Mannion R and Goddard M (2003) Public disclosure of comparative clinical performance data: lessons from the Scottish experience. Journal of Evaluation in Clinical Practice 9, 277-286.

Marshall MN, Shekelle PG, Brook R and Leatherman S (2000) Dying to Know: Public Release of Information about Quality of Health-Care. London: Nuffield Trust.

Marshall MN, Shekelle PG, Davies HTO and Smith PC (2003) Public reporting on quality in the United States and the United Kingdom. Health Affairs 22, 134-148.

McDonald R and Roland M (2009) Pay-for-performance in primary care in England and California: comparison of unintended consequences. Annals of Family Medicine 7, 121-127.

Meijer A (2009) Understanding modern transparency. International Review of Administrative Sciences 75, $255-269$.

Miller P (1992) Accounting and subjectivity: the invention of calculating selves and calculating spaces. Annals of Scholarship 9, 61-86.

Murray R (2017) The NHS Financial Regime: Cleverly Flexible or Horribly Messy? London: King's Fund.

Muzio D, Brock DM and Suddaby R (2013) Professions and institutional change: towards an institutionalist sociology of the professions. Journal of Management Studies 50, 699-721.

Ocasio W, Thornton PH and Lounsbury M (2017) The institutional logics perspective, chapter 19. In Greenwood R, Oliver C, Lawrence T and Meyer R (eds), The Sage Handbook of Organizational Institutionalism, 2nd Edn. London: Sage, pp. 509-521.

Oliver A and Brown L (2011) Incentivizing professionals and patients: a consideration in the context of the United Kingdom and the United States. Journal of Health Politics, Policy and Law 36, 59-87.

Parker JP and Damberg C (2005) The California Report on Coronary Artery Bypass Graft Surgery 2000-2002 Hospital Data. San Francisco, CA: California Office of Statewide Health Planning and Development and the Pacific Business Group on Health.

Pawson R (2002) Evidence and policy and naming and shaming. Policy Studies 23, 211-230.

Pelone F and Riccardi W (2013) Public reporting in health: reflections and proposal for a new operational tool. Quaderni dell Italian Journal of Public Health 2, 25-34.

Power M (1997) The Audit Society. Oxford: Oxford University Press.

Ritchie J and Spencer L (1994) Qualitative data analysis for applied policy research. Chapter 9. In Bryman A and Burgess RG (eds), Analyzing Qualitative Data. London: Routledge, pp. 173-194.

Roberts KJ (1999) Patient empowerment in the United States: a critical commentary. Health Expectations 2, 82-92.

Rosenthal MB and Dudley RA (2007) Pay-for-performance: will the latest payment trend improve care? Journal of American Medical Association 297, 740-744. 
Sanderson M, Allen P, Peckham S, Hughes D, Brown M, Kelly G, Baldie D, Mays N, Linyard A and Duguid A (2013) Divergence of NHS choice policy in the UK: what difference has patient choice policy in England made? Journal of Health Services Research \& Policy 18, 202-208.

Scott WR (2008) Lords of the dance: professionals as institutional agents. Organization Studies 29, 219-238.

Scott IA and Ward M (2006) Public reporting of hospital outcomes based on administrative data: risks and opportunities. Medical Journal of Australia 184, 571-575.

Shekelle PG, Lim Y-W, Mattke S and Damberg C (2008) Does Public Release of Performance Results Improve Quality of Care? London: Health Foundation.

Smith PC (1995) On the unintended consequences of publishing performance data in the public sector. International Journal of Public Administration 18, 277-310.

Strathern M (2000) The tyranny of transparency. British Educational Research Journal 26, 310-332.

Suddaby R and Viale T (2011) Professionals and field-level change: institutional work and the professional project. Current Sociology 59, 423-442.

Timmermans S and Oh H (2010) The continued social transformation of the medical profession. Journal of Health and Social Behavior 51, S94-S106.

Tritter JQ (2009) Revolution or evolution: the challenges of conceptualizing patient and public involvement in a consumerist world. Health Expectations 12, 275-287.

Tsoukas H (1997) The tyranny of light: the temptations and the paradoxes of the information society. Futures 29, 827-843.

Tu JV and Cameron C (2003) Impact of an acute myocardial infraction report card in Ontario, Canada. Canadian Medical Journal 15, 131-137.

Tuohy CH (1999) Accidental Logics: The Dynamics of Change in the Health Care Arena in the United States, Britain, and Canada. Oxford: Oxford University Press.

Walshe K (2001) Don't try this at home: health policy lessons for the NHS from the United States. Economic Affairs 21, 2832.

Waring J and Currie G (2009) Managing expert knowledge: organizational challenges and managerial futures for the UK medical profession. Organization Studies 30, 755-778.

Westaby S (2014) Publishing individual surgeons' death rates prompts risk averse behaviour. British Medical Journal 349, g5026.

Cite this article: Exworthy M, Gabe J, Rees Jones I, Smith G (2021). Explaining health system responses to public reporting of cardiac surgery mortality in England and the USA. Health Economics, Policy and Law 16, 183-200. https://doi.org/ $10.1017 /$ S1744133120000444 